\title{
The Characteristics of Fatigue Symptoms and Their Association with the Life Style and the Health Status in School Children
}

\author{
Mikizo Okamoto, Fengzhu Tan, Akihiko Suyama, Hirofumi Okada, Tetsuya Miyamoto, and \\ Takuji Kishimoto
}

\begin{abstract}
In order to evaluate the characteristics of fatigue symptoms and their association with the life style and the health status, we examined using data accumulated by the longitudinal surveys from 1992 to 1998, in 118 six-year primary school children and 129 second-year junior high school children.

The complaints of "Drowsiness and duliness", such as "Become drowsy" (71\%),"Give a yawn"(59\%) and "Want to lie down"(51\%), respectively, were most frequently observed. The proportion of these complaints was high before the first morning class, but decreased when the children leave school. Notably, the complaints of "Difficulty in concentration" annually have increased. Children with undesirable eating habits, particularly those who often eat salty foods, or poor life style, such as staying up late at night tended to have more complaints of fatigue symptoms. By correlation analysis, these complaints were significantly related to the obesity degree, blood pressure, HDL cholesterol and atherogenic index.

These results support the hypothesis that fatigue symptoms increase or are associated with life style and health status. Consequently, it is necessary to improve the life style such as dietary habits and rhythm of life for the reduction of fatigue symptom.
\end{abstract}

$J$ Epidemiol, $2000 ; 10: 241-248$.

fatigue symptoms, school children, longitudinal study dietary habits, rhythm of life, serum lipid, obesity

\section{INTRODUCTION}

It has been suggested that children of today, compared with 10 years ago, are "less patient" and easily say "I'm tired" and have problems in their basic life ${ }^{1-4)}$. In this background, changes in the living environment of children and disturbances in dietary and life style are considered. In particular, staying up late at night is associated with decreased appetite in the morning and skipping of breakfast, irregular defecation, and sleepiness from the morning.

These phenomena reflect the adult society and are no longer problems only in children and should be coped with as parentchild problems.

However, there have been only a few studies on the association between fatigue symptoms and the diet as well as life style ${ }^{5-9)}$ or the health status ${ }^{10-14)}$. In particular, there have been few such studies in primary and junior high school children.

As a part of preventive measures for life style related diseases in children in $\mathrm{H}$-cho of Shimane Prefecture, we have carried out since 1992 measurement of blood pressure, blood examinations, and various surveys of fatigue symptoms and life style.

Based on data accumulated by these longitudinal surveys over the 6-year period, we evaluated the characteristics of fatigue symptoms in children and their association with the life style in their background and the health status.

\section{SUBJECTS AND METHODS}

In $\mathrm{H}$-cho of Shimane Prefecture, we have carried out since

Received August 30, 1999 ; accepted December 18, 1999.

Department of Hygiene, Faculty of Medicine, Tottori University.

Address for correspondence : Mikizo Okamoto, Department of Hygiene, Faculty of Medicine, Tottori University, 86, Nishi-machi, Yonago, 683-8503 Japan. 
1992 various surveys, examinations and measurements in second-, fourth-, and sixth-year children of 3 primary schools and second-year children of 1 junior high school. In this study, considering the ability of children to understand fatigue items, second- and fourth-year primary school children were excluded, and the subjects consisted of only six-year primary school children and second-year junior high school children. The association between the health status and fatigue symptoms or life style was evaluated using only data in 1998. The subjects in the survey in 1998 were 123 sixth-year primary school children and 143 second-year junior high school children, but the subjects for final analysis were 247 children consisting of 118 sixth-year primary school children (58 males and 60 females) and 129 second-year junior high school children ( 55 males and 74 females) because of eliminating some incomplete respondents to the questionnaires of surveys.
The investigation period was 6 years from 1992 to 1998. We asked each school via the Board of Education of the town to annually carry out a survey on about Wednesday at the same time of the year (about June), considering daily and weekly variations ${ }^{15-18}$. Since a date without special school events was selected, the effects of the survey methods appeared to be slight.

The "questionnaire of fatigue symptoms" consisting of 30 items that was produced by the Industrial Fatigue Society ${ }^{19} 21$ ) was used without changes. The children replied to the questionnaire with their signature during the homeroom hour twice (when arriving at school and before leaving school). For analysis, we classified fatigue symptoms into 3 groups (Group I: Drowsiness and dullness, Group II: Difficulty in concentration, Group III: Projection of physical disintegration) (Table 1). The life style items included the average ingestion frequencies of 8

Table 1. Comparison of the complaint proportion of each fatigue symptom at morning or leaving school in school children.

\begin{tabular}{|c|c|c|}
\hline fatigue symptom item & morning & leaving school \\
\hline 1. Feel heavy in head & $8.3 \%$ & $5.6 \%$ \\
\hline 2. Get tired of the whole body & 35.7 & 22.2 \\
\hline 3. Get tired of the legs & 12.8 & 13.2 \\
\hline 4. Give a yawn & 62.4 & 35.3 \\
\hline 5. Feel the brain hot or muddled & 16.5 & 13.5 \\
\hline 6. Become drowsy & 73.3 & 41.4 \\
\hline 7. Feel strained in the eyes & 25.6 & 26.7 \\
\hline 8. Become rigid or clumsy in motion & 3.0 & 2.6 \\
\hline 9. Feel unsteady in standing & 1.9 & 2.6 \\
\hline 10. Want to lie down & 37.6 & 26.7 \\
\hline total in Group I & 27.7 & 19.0 \\
\hline 11. Feel difficult in thinking & 13.2 & 8.6 \\
\hline 12. Become weary of talking & 10.2 & 5.3 \\
\hline 13. Become nervous & 18.4 & 12.8 \\
\hline 14. Unable to concentrate attention & 10.9 & 5.3 \\
\hline 15. Unable to have interest in things & 16.5 & 7.9 \\
\hline 16. Become apt to forget things & 15.4 & 9.8 \\
\hline 17. Lack of self-confidence & 5.3 & 4.1 \\
\hline 18. Anxious about things & 6.8 & 6.8 \\
\hline 19. Unable to straighten up in a posture & 18.4 & 9.4 \\
\hline 20. Lack of patience & 11.3 & 9.4 \\
\hline total in Group II & 12.6 & 7.9 \\
\hline 21. Have a headache & 8.6 & 10.9 \\
\hline 22. Feel stiff in the shoulders & 29.3 & 23.3 \\
\hline 23. Feel a pain in the back & 13.9 & 12.8 \\
\hline 24. Feel oppressed in breathing & 3.4 & 1.9 \\
\hline 25. Feel thirsty & 19.2 & 25.9 \\
\hline 26. Have a husky voice & 10.5 & 7.5 \\
\hline 27. Have a dizziness & 5.6 & 5.3 \\
\hline 28. Have a spasm on the eyelids & 6.4 & 1.9 \\
\hline 29. Have a tremor in the limbs & 1.9 & 2.3 \\
\hline 30. Feel ill & 7.1 & 4.9 \\
\hline total in group III & 10.6 & 9.7 \\
\hline total in all groups & 17.0 & 12.2 \\
\hline
\end{tabular}


types of food per week, ingestion frequencies of instant, boilin-the-bag food, juice, refreshing drinks, and confectionery, eating habits (salty food, breakfast, afternoon snacks, supper, and late-night snacks), bedtime, sleeping hours, sports, outdoor play, and television, family computer games. The following scoring was done for food ingestion: : no ingestion in a week ( 0 point), ingestion on 1 or 2 days ( 2 points), 3 or 4 days ( 3 points), 5 or 6 days ( 4 points), and every day ( 5 points). The ingestion frequency scores for 8 types of food were totaled.

Blood pressure was measured using a manchette applied to the brachium 3 times at rest, and the mean of the latter two values was obtained as the measurement value.

The items of blood examination were hemoglobin $(\mathrm{Hb})$ and hematocrit $(\mathrm{Ht})$ for examination of anemia and total cholesterol (TC), HDL cholesterol (HDL), and atherogenic index (AI)= (TC - HDL) / HDL for examination of senum lipids.

The obesity degree was calculated by obtaining the standard body weight using the age coefficient of Murata's primary regression equation for height and body weight ${ }^{22}$.

The selection proportion of each item of fatigue symptoms, the complaint proportion according to fatigue symptom groups, and the number of complaints per child were calculated.

Concerning the association between fatigue symptoms and the diet or life style, the complaint number of fatigue symptoms per person was classified into 3 categories $(0-3,4-6$, and 7 and more) by tertile, and comparison was made by the Cochran-Mantel-Heanszel test (CMH) of the SAS and covariance analysis of the GLM procedure with adjustment of sex and age.

As factor analysis of dietary and life style that may affect fatigue symptoms, multiple regression analysis was performed using the complaint number of fatigue symptoms as an objective variable and 16 dietary factors and living habit factors as explanatory variables. All variables other than the complaint number of fatigue symptoms, food ingestion score, and sleeping hours were ordinal variables of 3 to 5 category data.

The association between the health status and fatigue symp- toms, diet, or the life style was analyzed by Spearman's correlation coefficient, considering normal distribution.

\section{RESULTS}

\section{Present status and characteristics of fatigue symptoms}

Concerning fatigue symptoms before the first class in the morning (Table 1), the complaint proportion was the highest for Group I symptoms characterized by tiredness and languor, followed in order by Group II and Group III. In each Group, the following items were frequently observed. Group I: "Become drowsy" (71\%), "Give a yawn" (59\%), "Want to lie down" (50\%); Group II: "Unable to have interest in things", "Lack patience" and "Become nervous"; and Group III: "feel thirsty", "Feel stiff in the shoulders", and "Feel a pain in the back".

The mean number of complaints per person was 5.1. Only 4 children did not complain of any item.

As shown in Table 1, the complaint proportion of fatigue symptoms was high before the first morning class but decreased when the children leave school. Especially marked decreases were observed in "Become drowsy" $(73.3 \% \rightarrow$ $41.4 \%)$, "Give a yawn" $(62.4 \% \rightarrow 35.3 \%)$, "Want to lie down" and "Get tired of the whole body" in Group I. Conversely, the complaint proportion for "Feel thirsty" increased $(19.2 \% \rightarrow$ $25.9 \%$ ) especially in the six-year primary school children.

\section{Annual changes in fatigue symptoms}

Annual changes in the complaint proportion from 1992 to 1998 were evaluated (Table 2). The complaint proportion tended to increase in both sixth-year primary school children and second-year junior high school children, especially markedly in the former. In the primary school children, the complaint proportion of Groups I, II, and III symptoms in 1998 showed a 2- - 3-fold increase over 1992. In the junior high school children, Group I symptoms showed a gradual increase while Groups II and III leveled off. In particular, in 1998, the complaint proportion of Group II symptoms in the six-year primary

Table 2. Annual change in the complaint proportion by Group.

\begin{tabular}{lccccc}
\hline & Group* & 1992 & 1994 & 1996 & 1998 \\
\hline \multirow{3}{*}{ primary } & I & $16.6 \%$ & $23.9 \%$ & $22.3 \%$ & $26.7 \%$ \\
school & II & 6.9 & 8.5 & 10.9 & 16.9 \\
& III & 4.5 & 6.8 & 7.6 & 12.0 \\
& total & 9.4 & 13.0 & 13.6 & 18.6 \\
\hline \multirow{2}{*}{ junior } & I & $25.0 \%$ & $24.1 \%$ & $31.5 \%$ & $28.5 \%$ \\
high & II & 7.7 & 6.5 & 12.9 & 9.0 \\
school & III & 7.9 & 7.2 & 8.0 & 9.4 \\
& total & 13.5 & 12.6 & 17.5 & 15.6 \\
\hline Total & & $11.4 \%$ & $12.8 \%$ & $15.5 \%$ & $17.0 \%$ \\
\hline
\end{tabular}

* : Group I concerning "drowsiness and dullness", Group II concerning "difficulty of concentration" and Group III concerning "projection of physical disintegration" 
school children (16.9\%) was about twice that in the secondyear junior high school children (9.0\%). Though data are not shown in this study, marked differences were observed in "Unable to straighten up in a posture", "Become apt to forget things", "Feel difficult in thinking", "Become nervous", and "Unable to concentrate attention" classified as Group II characterized by difficulty in concentration.

\section{Association between life style and the complaint number of fatigue symptoms}

(1) Association between the food ingestion frequency, the eating habits and fatigue symptoms

As shown in Table 3, the adjusted mean complaint number of fatigue symptoms was the highest (7.12/person) in the children who "often eat" salty food and the lowest (4.66) in those who "seldom eat" salty food. No significant relationship was observed between the complaint number and the other dietary factors. However, children with 7 and more complaint num- bers accounted for a high percentage in children who "seldom have" or "sometimes have" breakfast and in those who "often have" or "sometimes have" late-night snacks.

(2) Association between exercise - physical activities and fatigue symptoms

In children who practice "no sports" except physical education classes, those with 7 and more complaint numbers accounted for $35.0 \%$ (Table 4 ). Conversely, children who "often practice" sports had fewer complaints ( $p=0.027)$.

In children who "seldom play" outdoors after coming home from school, those with 7 and more complaint numbers accounted for $29.7 \%$. On the other hand, the complaint number was slightly lower in children who play outdoors "every day" (Table 4).

(3) Rhythm of life

As shown in Table 4, in children who stay up late at night "every day", those with 7 and more complaint numbers accounted for $47.6 \%$, and the mean adjusted complaint number

Table 3. Association between the food ingestion frequency, eating habits and complaint number of fatigue symptom.

\begin{tabular}{|c|c|c|c|c|c|c|c|c|c|}
\hline \multirow[b]{2}{*}{ Item } & \multirow[b]{2}{*}{ frequency } & \multirow[b]{2}{*}{ number } & \multicolumn{3}{|c|}{ complaint number } & \multirow[b]{2}{*}{$\mathrm{CMH}$-test*a } & \multicolumn{3}{|c|}{ complaint number*b } \\
\hline & & & $0-3$ & $3-6$ & $7-$ & & adjusted mean & adjusted sd & covariance analysis \\
\hline \multirow[t]{3}{*}{ breakfast } & every day & 231 & $37.2 \%$ & $35.5 \%$ & $27.3 \%$ & ns & 5.09 & 0.23 & $\mathrm{df}=2$ \\
\hline & sometimes & 15 & $33.3 \%$ & $33.3 \%$ & $33.3 \%$ & & 6.03 & 0.92 & $F=0.59$ \\
\hline & 0 day & 1 & $0.0 \%$ & $100.0 \%$ & $0.0 \%$ & & 3.52 & 3.56 & $\mathrm{p}=0.553$ \\
\hline \multirow[t]{3}{*}{ salty food } & seldom & 113 & $43.4 \%$ & $33.6 \%$ & $23.0 \%$ & $*$ & 4.66 & 0.33 & $\mathrm{df}=2$ \\
\hline & sometimes & 126 & $32.5 \%$ & $38.1 \%$ & $29.4 \%$ & & 5.45 & 0.31 & $F=2.78$ \\
\hline & often eat & 8 & $12.5 \%$ & $25.0 \%$ & $62.5 \%$ & & 7.12 & 1.25 & $p=0.064$ \\
\hline juice & 0 day & 120 & $35.8 \%$ & $35.0 \%$ & $29.2 \%$ & ns & 5.17 & 0.33 & $\mathrm{df}=2$ \\
\hline coca cola & 3-6 days & 96 & $35.4 \%$ & $37.5 \%$ & $27.1 \%$ & & 5.29 & 0.37 & $F=0.48$ \\
\hline refreshing drink & every day & 31 & $45.2 \%$ & $32.3 \%$ & $22.6 \%$ & & 4.57 & 0.64 & $\mathrm{p}=0.617$ \\
\hline confectionary & 0 day & 86 & $40.7 \%$ & $27.9 \%$ & $31.4 \%$ & ns & 5.21 & 0.38 & $d f=2$ \\
\hline \multirow{2}{*}{ snacks } & 3-6 days & 102 & $32.0 \%$ & $40.2 \%$ & $27.9 \%$ & & 5.32 & 0.32 & $F=0.99$ \\
\hline & every day & 39 & $43.6 \%$ & $38.5 \%$ & $17.9 \%$ & & 4.42 & 0.57 & $\mathrm{p}=0.374$ \\
\hline \multirow[t]{3}{*}{ supper with families } & always & 142 & $34.5 \%$ & $40.8 \%$ & $24.6 \%$ & ns & 4.89 & 0.30 & $\mathrm{df}=2$ \\
\hline & almost & 102 & $39.2 \%$ & $29.4 \%$ & $31.4 \%$ & & 5.50 & 0.36 & $F=0.85$ \\
\hline & alone & 3 & $66.7 \%$ & $0.0 \%$ & $33.3 \%$ & & 4.85 & 2.05 & $\mathrm{p}=0.427$ \\
\hline \multirow[t]{3}{*}{ late-night snacks } & seldom & 201 & $36.3 \%$ & $39.3 \%$ & $24.4 \%$ & ns & 5.01 & 0.25 & $\mathrm{df}=2$ \\
\hline & sometimes & 28 & $39.3 \%$ & $21.4 \%$ & $39.3 \%$ & & 5.32 & 0.67 & $F=1.17$ \\
\hline & every day & 18 & $38.9 \%$ & $16.7 \%$ & $44.4 \%$ & & 6.32 & 0.84 & $\mathrm{p}=0.311$ \\
\hline \multirow[t]{4}{*}{ food ingestion score } & $14-29$ & 132 & $40.0 \%$ & $35.7 \%$ & $24.3 \%$ & ns & 4.84 & 0.41 & $\mathrm{df}=3$ \\
\hline & $30-32$ & 65 & $26.2 \%$ & $38.5 \%$ & $35.4 \%$ & & 5.72 & 0.44 & $F=0.89$ \\
\hline & $33-35$ & 38 & $38.6 \%$ & $40.4 \%$ & $21.1 \%$ & & 4.83 & 0.47 & $\mathrm{p}=0.446$ \\
\hline & $36-40$ & 159 & $43.6 \%$ & $27.3 \%$ & $29.1 \%$ & & 5.10 & 0.48 & \\
\hline
\end{tabular}

$*_{\mathrm{a}}$ : adjusted for sex and school class using CMH(Cochran-Mantel-Heanszel) test

*b : adjusted for sex and school year using covariance analysis

$*: \mathrm{p}<0.10 \quad * *: \mathrm{p}<0.05 \quad \mathrm{~ns}:$ not significant $\quad \mathrm{sd}:$ standard deviation 
Table 4. Association between life style and complaint number of fatigue symptom.

\begin{tabular}{|c|c|c|c|c|c|c|c|c|c|}
\hline \multirow[b]{2}{*}{ Item } & \multirow[b]{2}{*}{ frequency } & \multirow[b]{2}{*}{ number } & \multicolumn{3}{|c|}{ complaint number } & \multirow[b]{2}{*}{ CMH-test*a } & \multicolumn{3}{|c|}{ complaint number*b } \\
\hline & & & $0-3$ & $3-6$ & $7-c$ & & adjusted mean & adjusted sd & covariance analysis \\
\hline staying up late & scarcely & 108 & $44.4 \%$ & $32.4 \%$ & $23.1 \%$ & $* *$ & 4.41 & 0.34 & $\mathrm{df}=2$ \\
\hline \multirow{2}{*}{ at night } & sometimes & 118 & $33.1 \%$ & $39.0 \%$ & $28.0 \%$ & & 5.44 & 0.32 & $F=6.61$ \\
\hline & every day & 21 & $19.0 \%$ & $33.3 \%$ & $47.6 \%$ & & 7.25 & 0.76 & $\mathrm{p}=0.002$ \\
\hline sports other than & 4 days $=<$ & 162 & $40.1 \%$ & $34.0 \%$ & $25.9 \%$ & ns & 5.08 & 0.28 & $\mathrm{df}=2$ \\
\hline \multirow[t]{2}{*}{ those as classes } & 1-3days & 45 & $37.8 \%$ & $35.6 \%$ & $26.7 \%$ & & 4.26 & 0.56 & $F=3.66$ \\
\hline & 0 day & 40 & $22.5 \%$ & $42.5 \%$ & $35.0 \%$ & & 6.35 & 0.57 & $\mathrm{p}=0.027$ \\
\hline \multirow[t]{3}{*}{ outdoor plays } & every day & 63 & $33.3 \%$ & $47.6 \%$ & $19.0 \%$ & ns & 4.42 & 0.46 & $\mathrm{df}=2$ \\
\hline & sometimes & 120 & $38.3 \%$ & $30.8 \%$ & $30.8 \%$ & & 5.30 & 0.32 & $F=1.69$ \\
\hline & seldom & 64 & $37.5 \%$ & $32.8 \%$ & $29.7 \%$ & & 5.56 & 0.45 & $\mathrm{p}=0.188$ \\
\hline \multirow{3}{*}{$\begin{array}{l}\text { TV watching } \\
\text { hours }\end{array}$} & $<1 \mathrm{~h}$ & 26 & $46.2 \%$ & $34.6 \%$ & $19.2 \%$ & ns & 4.21 & 0.70 & $d f=2$ \\
\hline & $1-3 h$ & 182 & $37.4 \%$ & $35.7 \%$ & $26.9 \%$ & & 5.09 & 0.26 & $F=2.06$ \\
\hline & $4 h=<$ & 39 & $28.2 \%$ & $35.9 \%$ & $35.9 \%$ & & 6.01 & 0.57 & $\mathrm{p}=0.130$ \\
\hline \multirow{3}{*}{$\begin{array}{l}\text { family computer } \\
\text { games }\end{array}$} & $0-1$ day & 126 & $39.7 \%$ & $33.1 \%$ & $27.2 \%$ & $*$ & 4.99 & 0.3 & $\mathrm{df}=2$ \\
\hline & $2-4$ days & 109 & $36.9 \%$ & $41.7 \%$ & $21.4 \%$ & & 4.74 & 0.38 & $F=5.17$ \\
\hline & 5 days $=<$ & 12 & $22.2 \%$ & $29.6 \%$ & $48.1 \%$ & & 7.16 & 0.67 & $\mathrm{p}=0.006$ \\
\hline \multirow[t]{4}{*}{ sleeping hours } & $6-7 \mathrm{~h}$ & 14 & 35.7 & 42.9 & 21.4 & ns & 4.78 & 0.84 & $\mathrm{df}=3$ \\
\hline & $7-8 \mathrm{~h}$ & 50 & 40.0 & 38.0 & 22.0 & & 4.95 & 0.54 & $F=2.06$ \\
\hline & $8-9 h$ & 127 & 38.6 & 33.1 & 28.3 & & 5.12 & 0.32 & $\mathrm{p}=0.130$ \\
\hline & $9 \mathrm{~h}=<$ & 56 & 30.4 & 37.5 & 32.1 & & 5.41 & 0.49 & \\
\hline
\end{tabular}

*a : adjusted for sex and school class using $\mathrm{CMH}$ (Cochran-Mantel-Heanszel) test

*b : adjusted for sex and school year using covariance analysis

$*: \mathrm{p}<0.10 \quad * *: \mathrm{p}<0.05 \quad \mathrm{~ns}:$ not significant $\mathrm{sd}:$ standard deviation

was 7.25 person. In children who "seldom" stay up late at night, those with 7 and more complaint numbers accounted for $23.1 \%$, and the adjusted mean complaint number was 4.41 . The complaint number significantly differed according to the frequency of staying up late at night $(\mathrm{p}<0.002)$.

There was no association between sleeping hours or TV watching hours and the complaint number.

A significant relationship was observed between the frequency of playing family computer games and the complaint number. The mean adjusted complaint number was 7.16/person in children who play family computer games on " 5 days or more" but 4.99 in those who play them on "0 - 1 day".

\section{Association between life style and the complaint number of fatigue symptoms by multiple regression analysis}

Multiple regression analysis was performed using the complaint number as an objective variable and 16 dietary and living factors involving sex and the school year as explanatory variables with stepwise procedure.

Item category of these explanatory variables was the same as that of Table 3 and 4 . The results were significant when the multiple regression coefficients was 0.270 , the coefficient of determination was 0.073 , and the $p$ value was $<0.016$. As shown in Table 5, a significant partial regression coefficient for entry into the model with 0.5 significant level was obtained only for the following 7 explanatory variables: sex, juice . refreshing drinks, salty food, sleeping hours, staying up late at night, sports and outdoor plays. In particular, the frequency of staying up late at night showed the highest partial R-square for the complaint number of fatigue symptoms $(\mathrm{p}<0.01)$.

\section{Associations between the health status and fatigue symptoms or life style}

As shown in Table 6, the complaint number of fatigue symptoms in the morning was significantly correlated with the obesity degree, HDL, as well as AI. Among dietary habits, the ingestion frequency of salty food was correlated with $\mathrm{Ht}$ as well as HDL, and the frequency of skipping breakfast was significantly correlated with the obesity degree, the minimum blood pressure, as well as AI. Among living factors, there were significant correlations between the frequency of staying up late at night and the maximum blood pressure, between the frequency of not practicing sports and the obesity degree, minimum blood pressure, HDL, as well as AI, and between the frequency of not playing outdoors and the maximum as well as minimum blood pressure, and between the TV watching hours 
Table 5. Relationship between life style and the complaint number of fatigue symptoms evaluated by multiple regression analysis using stepwise procedure.

\begin{tabular}{|c|c|c|c|}
\hline multiple correlation coefficient & $\begin{array}{l}\text { coefficient of } \\
\text { determination }\end{array}$ & observed number & significant level \\
\hline 0.270 & 0.0728 & 232 & 0.0162 \\
\hline selected explanatory variables* & partial R-square & model R-square & p value \\
\hline frequency of staying up late at night frequency of drinking juice, refreshing drinks & 0.0313 & 0.0313 & 0.0068 \\
\hline frequency of sports other than those & 0.0125 & 0.0438 & 0.0842 \\
\hline as classes & 0.0133 & 0.0571 & 0.0737 \\
\hline sex & 0.0044 & 0.0615 & 0.3027 \\
\hline sleeping hours & 0.0051 & 0.0666 & 0.2685 \\
\hline frequency of eating salty food & 0.0038 & 0.0703 & 0.3388 \\
\hline frequency of outdoor plays per week & 0.0024 & 0.0728 & 0.4434 \\
\hline
\end{tabular}

* : these variables met for entry into the model with 0.5 significant level

Table 6 . Associations between the health status and fatigue symptoms or life style by Spearman's correlation coefficients.

\begin{tabular}{|c|c|c|c|c|c|c|c|c|c|}
\hline & $\begin{array}{l}\text { obesity } \\
\text { degree }\end{array}$ & SBP & DBP & $\mathrm{Hb}$ & $\mathrm{Ht}$ & $\mathrm{TC}$ & HDL & AI & School year \\
\hline $\begin{array}{l}\text { complaint number in } \\
\text { the morning }\end{array}$ & $0.120^{*}$ & -0.068 & -0.044 & 0.074 & 0.050 & -0.017 & $-0.138 * *$ & $0.139 * *$ & $-0.12 l^{* *}$ \\
\hline $\begin{array}{l}\text { frequency of eating } \\
\text { salty food }\end{array}$ & 0.040 & 0.031 & 0.008 & 0.050 & $0.111 *$ & -0.017 & $-0.130 * *$ & 0.092 & 0.076 \\
\hline $\begin{array}{l}\text { frequency of having no } \\
\text { breakfast }\end{array}$ & $0.113^{*}$ & 0.049 & $0.173 * *$ & 0.041 & 0.049 & 0.077 & -0.088 & $0.108^{*}$ & -0.026 \\
\hline $\begin{array}{l}\text { frequency of staying } \\
\text { late at night }\end{array}$ & 0.087 & $0.153 * *$ & -0.047 & 0.026 & 0.049 & -0.022 & -0.032 & 0.007 & $0.172^{* *}$ \\
\hline $\begin{array}{l}\text { frequency of not } \\
\text { practicing sports }\end{array}$ & $0.191 * * *$ & 0.009 & 0.105 & 0.051 & 0.029 & 0.085 & $-0.188 * *$ & $0.237 * * *$ & * $-0.367 * * *$ \\
\hline $\begin{array}{l}\text { frequency of not } \\
\text { practicing outdoor } \\
\text { plays }\end{array}$ & 0.099 & $0.184 * *$ & 0.159 & 0.009 & 0.055 & 0.096 & -0.028 & 0.098 & $0.231 * * *$ \\
\hline TV watching hours & 0.085 & 0.009 & 0.012 & 0.011 & 0.028 & -0.041 & $-0.127^{*}$ & $0.109^{*}$ & $0.145^{*}$ \\
\hline $\begin{array}{l}\text { frequency of family } \\
\text { computer games }\end{array}$ & 0.013 & 0.007 & -0.049 & 0.023 & 0.034 & -0.035 & 0.000 & 0.021 & 0.021 \\
\hline
\end{tabular}

$*: \mathrm{p}<0.10, \quad * *: \mathrm{p}<0.05, \quad * * *: \mathrm{p}<0.01$

DBP : Diastolic blood pressure, SBP : Systolic blood pressure, Hb : Hemoglobin, Ht : Hematocrit, TC : Total cholesterol, HDL : High density lipoprotein, AI : Atherogenic index 
and $\mathrm{HDL}$ as well as Al. In general, many factors were significantly related to the obesity degree, blood pressure, $\mathrm{HDL}$, and AI.

\section{DISCUSSION}

The characteristics of fatigue symptoms in the primary and junior high school children showed a typical mental work type in adults. The complaints of drowsiness and dullness were most frequently observed, followed by group II complaints characterized by difficulty of concentration. These results were consistent with those in some previous studies ${ }^{15}, 16,23$ ). However, those complaints decreased when children leave school. This phenomenon is explained by diurnal change ${ }^{18}$ ) rather than healing of daily fatigue in school life.

Observation of annual changes in the complaint proportion from 1992 revealed an annual increase in the overall complaint proportion. Especially, the complaint proportion of Group II showed a more marked increase. This suggests that "children who can not study in a calm state", which is a current topic, are increasing.

However, since there have been no reports of this problem, it is important that the backgrounds of complaints such as "unable to straighten up in a posture", "become nervous", and "unable concentrate attention" are revealed.

Ikeda et al. ${ }^{11)}$ reported that their analysis by quantification theory II suggested a close association between the complaint number of fatigue symptoms and "regularity of the mealtime", "favorite tastes", "having or not having breakfast", and "balance of food ingestion" among kindergarten children (aged 3 6 years). Monden ${ }^{5,15,17}$ reported a high complaint proportion, especially that for Group II symptoms, both before and after classes in children who do not have breakfast among junior college female children, suggesting close involvement of skipping of breakfast in the complaint number of fatigue symptoms.

In this study, the percentage of children with a high complaint number and the adjusted mean number of complaints were significantly high in children who often eat "salty food".

However, the other items were not associated with the complaint number. In general, children with problems of the food ingestion frequency and eating habits tended to have more complaints.

Thus, these findings indicate the effects of dietary problems on fatigue symptoms.

Though the results of previous studies for sleeping hours have not always been consistent, many studies have shown a decrease in the complaint number with an increase in sleeping hours $5,6,15,24)$. However, with longer sleeping hours, the mean complaint number increased, and children who sleep for less than 6 - 7 hours showed the lowest number of complaints.

In particular, the frequency of staying up late at night showed the highest partial correlation coefficient $(p<0.01)$ by multiple regression analysis. There have been few studies on the effects of staying up late at night, but disturbances in the life style reflecting the present age such as night owl-type life . reversal of day and night may be a major cause of the increase in the complaint number. In particular, staying up late at night induces disturbance in the living rhythm, preventing good sleep, good appetite, and regular bowel movements, and may lead to skipping of breakfast, impaired defecation, and drowsiness and dullness.

Ikeda et al. ${ }^{11)}$ also reported that the percentage of children with a "high" fatigue symptom score was low in children who "move around" outdoors, "play outdoors both after coming home on weekdays and on Sundays".

In this study, children who frequently play outdoors showed a definitely lower complaint number than those who seldom play outdoors. However, the complaint number increased with a decrease in the frequency of outdoor plays. We speculate that the increase in the complaint number is due to not only a decrease in outdoor plays itself ${ }^{25}$, but also other factors in its background such as family computer games, TV, or extraschool lessons $\cdot$ cramming schools ${ }^{6}$.

By correlation analysis, the complaint was significantly related to the obesity degree, blood pressure, HDL, and AI. This finding suggests the relationship between the complaint number of fatigue symptoms and the health status. In its background, dietary factors and living factors appeared to be involved. Management of life such as the frequency of eating salty food or breakfast, staying up late at night, sleeping hours, and hours of playing family computer games and physical activities such as sports and outdoor plays markedly affects the relationship between the complaint number and the health status. Monden ${ }^{13)}$ suggested that living behavior problems, anxiety · affliction, and unhealthy are associated with an increase in the complaint number of fatigue symptoms, the complaint number is an important index for evaluation of the health status. Ikeda et al. ${ }^{10)}$ also indirectly demonstrated the relationship between blood properties and fatigue symptoms based on the relationship between fatigue symptoms and the diet and life style. These findings suggest that a fatigue symptom survey can be used as an important index in health management.

Tomita et al. ${ }^{7}$ suggested the marked effects of mental factors such as happy school life, the presence or absence of afflictions, and self-rating of the physique in females. Monden ${ }^{26)}$ reported an inverse correlation between the degree of satisfaction with life and feelings of fatigue in female junior college students. Further studies are necessary on the association of fatigue symptom with emotional and psychological items such as affliction and stress.

Our cohort study for 6 years from 1992 revealed that children in $\mathrm{H}$-cho in Shimane Prefecture have becoming more tired. In its background, the diet and life style appear to be closely involved. To improve fatigue symptoms, public health guidance should be given in dietary habits such as balanced ingestion of various types of food, avoidance of excessive 
ingestion of juice, refreshing drinks or salty food, and regular eating of breakfast. In the life style, a manual for realization of self life style management is necessary so that children can live a regular life with improvement in insufficient exercise, excessive family computer games, and frequent staying up late at night.

\section{REFERENCES}

1. Murata M. Children's problems and improvement in life style. Kenko Kanri, 1998;3:10-16(in Japanese).

2. Murata M. Children in 2001 are in danger series (3), Physical Health: 68-109, Froebel Kan, Tokyo, 1992(in Japanese).

3. Melnick A. When an adolescent is tired all the time. Consultant. 1981; 21: 150-154.

4. Montgomery G. Uncommon tiredness among college under- graduates. J Consult Clin Psychol 1983; 51: 517525.

5. Monden S. Study on the student health administration Daily living conditions and subjective fatigue symptoms. Jpn J School Health, 1978; 20:286-291(in Japanese).

6. lijima K, Kondo Y, Koyama T, Higurashi M. Effects of health status in children from attending a "JUKU". J P H, 1999; 46:343-350(in Japanese).

7. Lewis $\mathrm{G}$. Wessely $\mathrm{S}$. The epidemiology of fatigue: more questions than answer. J Epidemiol Com Health 1992; 46: 92-97.

8. Tomita T, Sasaki T, Komaru M. Relationship between life style and fatigue feeling in junior high school pupils. Jpn J Hyg, 1996; 51: 280(in Japanese).

9. Nishibe B, Nakayasu K. A research on the relation between the subjective symptoms of fatigue of children and their daily lives. Jpn J School Health, 1981;23:540550(in Japanese).

10. Ikeda J, Nagata H, Yoneyama K, Shishioka I. Dietary habits, life style and physical condition of junior high school children. J Jpn Soc Nutr Food Sci, 1994; 47: 131 138(in Japanese).

11. Ikeda J, Ando K. Dietary habit, life style and health conditions of pre-school children. Jpn J Pediatrics, 1997; 56: 69-83(in Japanese)

12. Monden S. A Study on feelings of fatigue (2) - living and health awareness and symptoms of fatigue - Health care, 1980; 21: 519-524(in Japanese).

13. Monden $S$. A study on the living control of junior high school pupils Influence of living behavior on the subjective symptom of fatigue. Jpn J P H, 1985; 32:25-35 (in
Japanese).

14. Monden S, Okuda $\mathrm{H}$, Hiraoka $\mathrm{Y}$. A study of the life style management of junior high school pupils (part 2) Relationship between subjective symptoms of fatigue, physical strength and life style behaviors. Jpn J P H, 1987; 34: 652-660(in Japanese).

15. Monden S. A study on feelings of fatigue in students - A few considerations of fatigue symptoms -, Health care, 1979; 21 : 421 - 426(in Japanese).

16. Maruyama S, Nakayasu K, Kume T, Seo K. Research studies of fatigue of children (I): Research on the actual conditions of subjective symptoms of fatigue (feelings of fatigue) of children in tokushima prefecture, the differences in feelings of fatigue between town children and children of mountains and the changes of a week. $J$ Gakugei, Tokushima Univ, 1979; 28: 37-52(in Japanese).

17. Monden S. Influence of skipping breakfast on symptoms of fatigue and flicker value, Health care, 1978; 20: 429 433(in Japanese).

18. Nakae $S$. On the diurnal change of subjective symptoms of fatigue in female students. Jpn J School Health, 1981; 23: 228-231(in Japanese).

19. Industrial Fatigue Society of Japanese Industrial Health Association: A report of "survey of symptoms of industrial fatigue" (1970), Science of labour, 1970; 25:12-62(in Japanese).

20. Piper BF. Dibble SL. Dodd MJ. Et al. The revised Piper Fatigue Scale. Psychometric evaluation in women with breast cancer. Nursing Diagnosis 1998; 4: 677-684.

21. Smets EMA. The multidimensional fatigue inventory(MFI) psychometric qualities of an instrument to assess fatigue. J Psycho Res 1995; 39: 315-325.

22. Murata M, Yamazaki K, Itani A, Inaba M. Standard body weight for height for age between 5 years and 17 years. Jpn J Pediatrics, 1980; 39: 93 -96(in Japanese).

23. Matsuura $H$, Ito $H$, Nakayasu $K$. Fatigue survey in high school students ${ }^{1)}$, Bulletin of Shikoku Women' University, 1978; No. 23: 43 - 55(in Japanese).

24. Nakae S. The influence of sleeping time on diurnal change of subjective symptoms of fatigue and flicker value in female students. Jpn J School Health,1985; 27: 46-50(in Japanese).

25. Framer M. Locke B. Moscicki E. et al. Physical activity and depressive symptoms: the NHANES 1 epidemiologic follow-up study. Am J Epidemiol 1988; 128: 1340-1351.

26. Monden $S$. Study on the student health administration Student life satisfaction and subjective fatigue symptoms. Jpn J Hyg. 1977; 32: 341 (in Japanese). 